\title{
Erratum to: Design Case Studies
}

\author{
Erratum to: \\ Chapter 4 in: C. Kabre, Sustainable Building Design, \\ Design Science and Innovation, \\ https://doi.org/10.1007/978-981-10-4618-6_4
}

In the original version of the book, the name "Uttam C. Jain" in the caption of Fig. 4.19 has to be replaced by "Dr. Vinod Gupta" in Chap. 4, which is a belated correction. The erratum chapter and the book have been updated with the change.

The updated online version of this chapter can be found at https://doi.org/10.1007/978-981-10-4618-6_4 